\title{
A comparison about the paddy fields applicability of two water stress index model by infrared automatic monitoring the canopy temperature of rice
}

\author{
Mingchao Gao,a, Shijie Gao1,Xiaohui Li1,Jiping Gao2, Jihong Li 1, \\ Wenzhong Zhang2, *, Yingshan Dong1,*
}

1 Crops Resources Research Institute, Jilin Academy of Agricultural Sciences, Northeast Agricultural Research Center of China,Changchun,136000

2Rice Research Institute, Key Laboratory of Northeast Rice Biology and Breeding, Ministry of Agriculture, Key Laboratory of Northern Japonica Rice Genetics and Breeding, Ministry of Education, Shenyang Agricultural University, Shenyang, 110866

aemail: gaomingchao99@qq.com, *Correspondingauthor: zwzhong@126.com

Keywords: Rice, Canopy Temperature, Crop Water Stress Index (CWSI), The Canopy-air Temperature Differences

\begin{abstract}
The canopy temperatures of rice were observed by the infrared temperature measuring equipment under different irrigation conditions in this experiment, and also it applied the CWSI empirical model and theoretical model to measure whether the crop were suffered from water stress or not. Meanwhile, in this paper, it gave a compare of these two models on the effect of monitoring rice water stress. The result showed that under non-ideal condition, the CWSI value of the empirical model was very volatile and often overflowed the range of 0 - 1 , however, the theoretical model was relatively stable. So it concluded that the CWSI theoretical model was much suitable for the application on monitoring the rice water stress. The results showed that the theoretical model has a good relation with the above indexes, and it can reflect the characteristics of the crop water stress. In addition, some practical experience and viewpoints were given in this paper.
\end{abstract}

\section{Introduction}

It is known that rice is an important grain crops, and also is one of the crops which needs more water, so the yield and quality of rice will be affected by long term water stress. It is significant for protecting the limited water resources and ensuring the yield and quality of rice by measuring the rice water deficit condition accurately and fast.

As a convenient technology which applied infrared automatic temperature measurement device to observe the canopy surface temperature of crop, so as to measure whether the crop suffered from the water stress or not, it has already developed maturely[1]. The CWSI has been frequently applied to quantify crop water stress based on canopy temperature over the past three decades (Gardner et al., 1992) [2], and it has also been used for irrigation management (Nielsen, 1990) [3]. Besides Jackson et al. (1988) [4] Möeller (2007) [5]used infrared thermal image to detect grape canopy water status. Alchanatis et al. (2010) [6] applied infrared thermal image to map the flow of water on cotton leaf. Susan OShaughnessy(2012)[7] established sorghum automatic irrigation model via the study of water stress index. Many experiments showed CWSI was feasible to estimate crop water demand.

Practically, the CWSI is divided into empirical model and theoretical model. The empirical model has few variables, simple using, but it sensitively influenced by the external environment, and it requires a lot of practice and operation experience. Yet the theoretical model needs more variables which increases the complex of use, however, for its powerful theoretical background, it can overcomes many defects of empirical model. In this test, it applied the crop water stress index CWSI to detect the water stress situation of rice, and compared the presentation of the empirical 
model and theoretical model on monitoring rice water stress which provided the basis for further application of the CWSI index.

\section{Materials and Methods}

The experiment took place at the test field of Rice Institute of Shenyang Agriculture University. ( $\mathrm{N} 41^{\circ} 8^{\prime} 、 \mathrm{E} 123^{\circ} 38^{\prime}$ ). Applied terrier 1 variety and established districts in the field by using plastic pool, and the properties of soil in this region is brown soil. The test established five different water gradient treatments, were: the field capacity of soil maximum water content $100 \%$ (building water courses, CK, corresponding soil water potential is 0 ), above $80 \%$ (corresponding soil water potential $0.025 \sim 0.03 \mathrm{MP}$ ), 60\%(corresponding soil water potential $0.045 \sim 0.05 \mathrm{MP}), \quad 40 \%$ (S3, corresponding soil water potential $0.055 \sim 0.06 \mathrm{MP}$ ), and $20 \%$ (S4, corresponding soil water potential below 0.08MP).

It used 023ABREB system from Campbell Company of the U.S. in the test, erected in the central area of the experimental field. The system was used to measure the sensor observations before update and calibration of the net radiation Rn, soil heat flux G, temperature, dew point, wind speed and etc. The datum acquisition happened 1 time per second, an average of 1 time every 20min, and stored them for output.

Canopy temperature, air temperature and humidity determination: it used Ti-125 infrared camera of FLUKE Company. U.S. To detect the temperature and humidity under the same canopy temperature by using the ZDR-20 temperature and humidity measuring instrument.

Crop water stress index (CWSI) can be defined as [8]

$$
\begin{aligned}
& \text { CWSI }=\frac{\left(T_{c}-T_{a}\right)-\left(T_{c}-T_{a}\right)_{l l}}{\left(T_{c}-T_{a}\right)_{u l}-\left(T_{c}-T_{a}\right)_{l l}} \\
& \left(T_{c}-T_{a}\right)_{l l}=A+B \cdot V P D \\
& \left(T_{c}-T_{a}\right)_{u l}=A+B \cdot V P G
\end{aligned}
$$

Where Tc is the crop canopy temperature, ${ }^{\circ} \mathrm{C}$; Ta is the air temperature ${ }^{\circ} \mathrm{C}$; $(\mathrm{Tc}-\mathrm{Ta})$ ll is the crop canopy-air difference under fully watered, the lower bound of canopy-air difference; (Tc-Ta)ul is the crop canopy-air difference under an acute shortage of water, the upper bound of canopy-air difference. A.B in the equation are empirical coefficients; VPD is the vapor pressure deficit hPa; VPG is the difference of vapor pressures when the temperature respectively at Ta and $\mathrm{Ta}+\mathrm{A}, \mathrm{hPa}$. The equation (1),(2),(3) are so called Idso's empirical model. Tc,Ta,VPD all can be detected by instrument. If we get the lower equation of empirical model then we can get VPD so as to achieve the CWSI. Ideally, the value of the CWSI should be at the range of $0 \sim 1$, when the crop fully watered, the CWSI value should be 0 , and the CWSI should be 1 as the crop has an acute shortage of water.

For its theoretical model, according to the monolayer energy balance resistance mode of canopy, it can deduce the upper and lower bound equation separately (1988, Jackson) [4].

$$
\begin{aligned}
& \left(T_{c}-T_{a}\right)_{l l}=\frac{r_{a}\left(R_{n}-G\right)}{\rho C_{P}} \cdot \frac{\gamma\left(1+r_{c p} / r_{a}\right)}{\Delta+\gamma\left(1+r_{c p} / r_{a}\right)}-\frac{V P D}{\Delta+\gamma\left(1+r_{c p} / r_{a}\right)} \\
& \left(T_{c}-T_{a}\right)_{u l}=\frac{r_{a}\left(R_{n}-G\right)}{\rho C_{P}}
\end{aligned}
$$

$\mathrm{Rn}$ is the net radiation of canopy, $\mathrm{W} / \mathrm{m}-2$; $\mathrm{G}$ is density of soil heat flux or flux density of canopy lower energy, $\mathrm{W} / \mathrm{m}-2$; $\mathrm{p}$ is the density of the air, $\mathrm{kg} / \mathrm{m}-3$; $\mathrm{Cp}$ is the air specific heat $\mathrm{J} /\left(\mathrm{kg}-\mathrm{I}^{\circ} \mathrm{C}-1\right) ; \gamma$ is the psychrometer constant, $\mathrm{Pa} /{ }^{\circ} \mathrm{C}-1 ; \Delta$ is the slope of the air saturated vapor pressure varies with temperature, $\mathrm{Pa} /{ }^{\circ} \mathrm{C}-1$; ra is the aerodynamic resistance, $\mathrm{s} / \mathrm{m}-1$; rcp is the water vapor diffusion resistance of the canopy under potential evaporation state, $\mathrm{s} / \mathrm{m}-1$, that is the minimum canopy resistance. 


\section{Results and discussion}

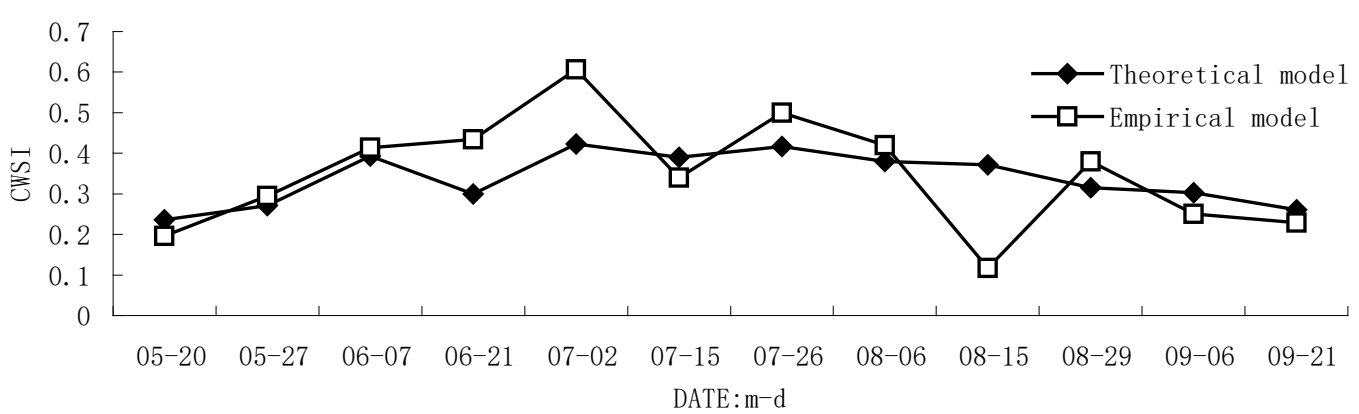

Fig.1 the CWSI values of the two models under CK treatment at 14:00

Fig. 1 is the CWSI values of the two models under the CK treatment at 14:00. From it, it can be seen that the theoretical model was much more stable than the empirical model, and there was no zero value of the CWSI appeared in the whole test under the CK treatment. Therefore, when it took the CWSI as an index on monitoring rice water stress, it should notes that it was a range of values not a single value.

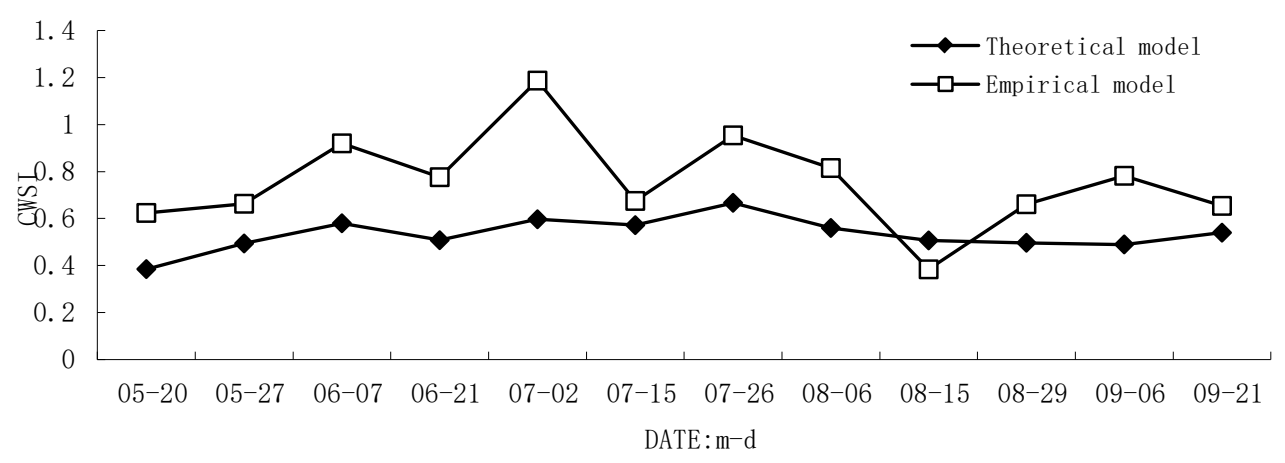

Fig.2 the CWSI values of the two models under S1 treatment at 14:00 in the whole growth

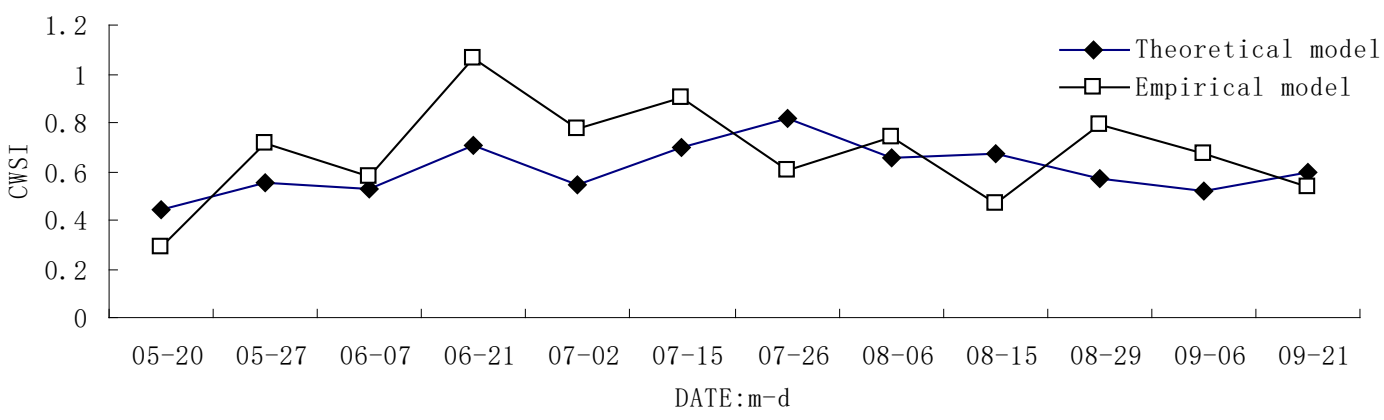

Fig.3 the CWSI values of the two models under S2 treatment at 14:00 in the whole growth 


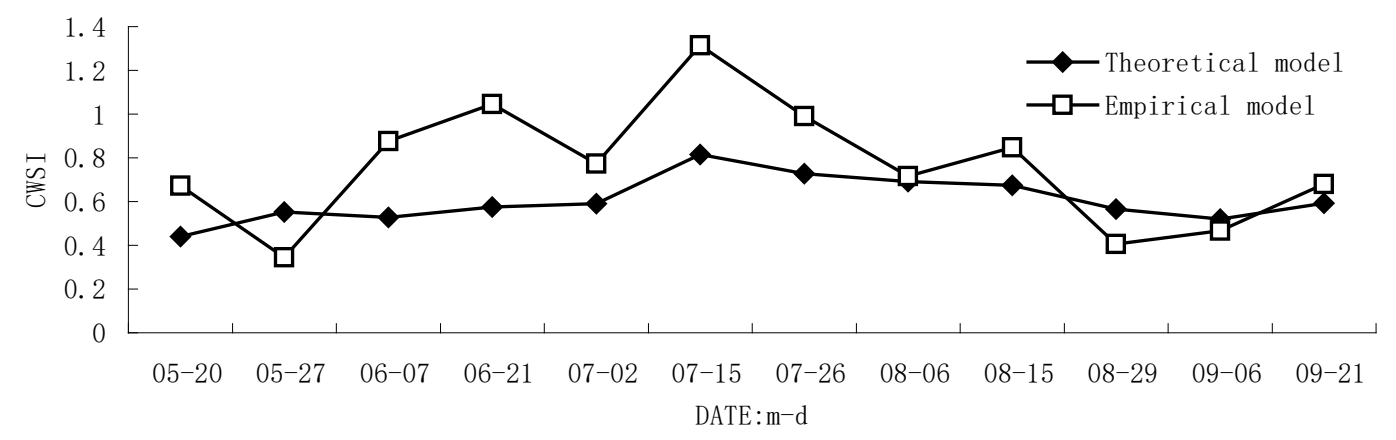

Fig.4 the CWSI values of the two models under S3 treatment at 14:00 in the whole growth

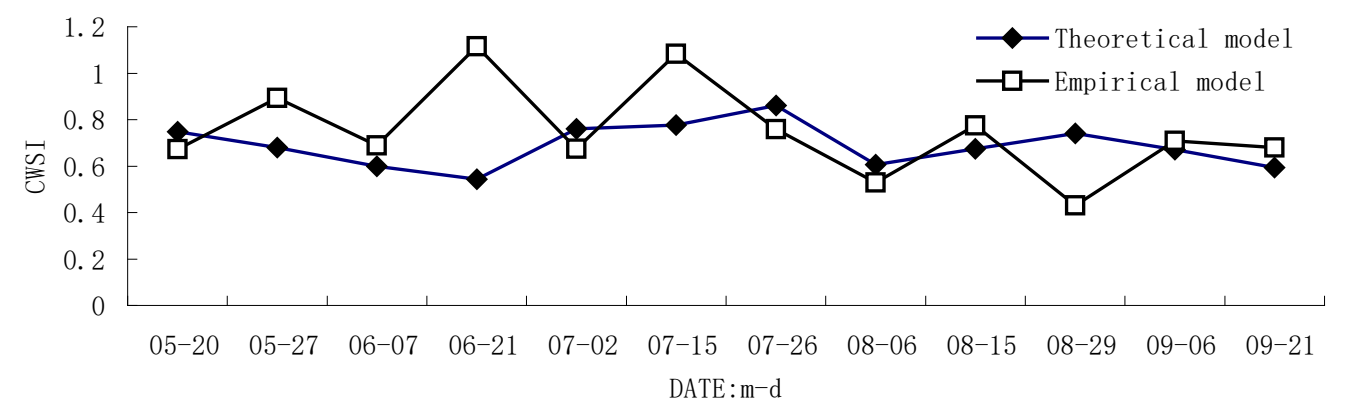

Fig.5 the CWSI values of the two models under S4 treatment at 14:00 in the whole growth The fig. 2 to fig 5 were respectively the CWSI values under the S1, S2, S3, S4 treatment at 14:00 in the whole growth, it expressed in contrast that the theoretical model was much more stable, and in the empirical model, the values overflowed the range of $0-1$. For the empirical model, the variation of the external environment would directly influence the modulus change of the regression equation which led the variation of the CWSI values. So in practical application, the moving average statistical form of parallel days should be in consideration in empirical model, because it can smooth the large fluctuations of the empirical model. In the theoretical model, the differences of the canopy temperature on upper and lower bound had good dynamics, as long as it measured stable datum, and calculated accurate canopy resistance, also the canopy enough confined to meet values condition, thus the values obtained from the canopy theoretical model would be reasonable. Consequently, the theoretical model can better response to the crop water deficit situation caused by soil moisture and atmospheric conditions.

\section{CONCLUSIONS}

It simultaneously applied the empirical model and theoretical model of the CWSI in the rice water stress. According to the observation in this experiment, the research got the calculating on the relationship between the differences of the canopy temperature and the differences of the air saturation vapor pressure in the CWSI empirical model, and also the calculating on the relationship between the canopy resistance and other meteorological indicators in the theoretical model. Then after comparing the differences of these two kinds of models, it founded that the empirical model can normally used at an ideal weather condition, once the external environment changed, the CWSI values would overflowed the range of $0-1$. And the theoretical model was much more stable than the empirical model, thus the theoretical model was much more suitable for reflecting the crop water deficit situation. 


\section{Acknowledgments}

This research was funded by A Doctoral Project of the Academy of Agriculture Sciences in Jilin, The plan LR2015060 about outstanding qualified scientists and technicians of colleges and univercities in Liaoning province,The Porject on Teachers (Youth)Research Foundation of Shengyang Agricultural University (20131009), and also the Cultivation Plan for Youth Agricultural Science and Technology Innovative Talents of Liaoning Province(2014039).

\section{References}

[1]Jackson R D. Canopy temperature and crop water stress[M]. In: Hillel D ed. Advances in Irrigation. Academic Press, New York, 1982,1:43-85.

[2]Gardner, B.R., Nielsen, D.C.,Shock, C.C., Infrared thermometry and the crop water stress index. I. History, theory, and baselines[J]. Journal of Production Agriculture.1992.a5,462-466.

[3] Nielsen,D.C., Scheduling irrigations for soybeans with the Crop Water Stress Index (CWSI) [J]. Field Crops Research.1990.23, 103-116.

[4] Jackson, R.D., Kustas, W.P., Choudhury, B.J., A reexamination of the crop water stress index[J]. Irrigation Science.1988.9, 309-317

[5] Möller M, Alchanatis V, Cohen Y, et al. Use of ther-mal and visible imagery for estimating crop water status of irrigated grapevine[J]. Journal of Experimental Botany, 2007, 58(4): 827-838.

[6] Alchanatis, V, Cohen Y, Cohen S, et al. Evaluationof different approaches for estimating and mapping crop water status in cotton with thermal imaging[J]. Precision Agriculture, 2010, 11: 27-41.

[7] Susan A. O’Shaughnessy., Steven R. Evett, Paul D. Colaizzi, Terry A. Howell A crop water stress index and time threshold for automatic irrigation scheduling of grain sorghum[J].Agricultural Water Management. 2012.107, 122-132

[8] Idso, S.B., Non-water-stressed baselines: a key to measuring and interpreting plant water stress[J]. Agriculture Meteorology.1982. 27, 59-70. 